\title{
BMJ Global Health Protecting the poor? Impact of the national health equity fund on utilization of government health services in Cambodia, 2006-2013
}

\author{
Peter Leslie Annear, ${ }^{1}$ John Tayu Lee, ${ }^{2}$ Keovathanak Khim (D) ${ }^{3}$ Por $\mathbf{~ I r , ~}{ }^{4}$ \\ Ellen Moscoe, ${ }^{5}$ Tapley Jordanwood, ${ }^{6}$ Thomas Bossert, ${ }^{5}$ Matthias Nachtnebel, ${ }^{1}$ \\ Veasnakiry $\mathrm{Lo}^{7}$
}

\begin{abstract}
To cite: Annear PL, Tayu Lee J, Khim K, et al. Protecting the poor? Impact of the national health equity fund on utilization of government health services in Cambodia, 2006-2013. BMJ Global Health 2019;4:e001679. doi:10.1136/ bmjgh-2019-001679
\end{abstract}

Handling editor Sanni Yaya

Received 12 May 2019

Revised 25 September 2019 Accepted 12 October 2019

Check for updates

(c) Author(s) (or their employer(s)) 2019. Re-use permitted under CC BY-NC. No commercial re-use. See rights and permissions. Published by BMJ.

${ }^{1}$ Nossal Institute, University of Melbourne, Melbourne, Victoria, Australia

${ }^{2}$ School of Population and Global Health, University of Melbourne, Melbourne, Victoria, Australia ${ }^{3}$ Public Health Department, University of Health Sciences, Phnom Penh, Cambodia ${ }^{4}$ National Institute of Public Health, Phnom Penh, Cambodia ${ }^{5}$ Harvard T.H. Chan School of Public Health, Boston, Massachusetts, United States ${ }^{6}$ University Research Co., LLC, Phnom, Cambodia

${ }^{7}$ Department of Planning and Health Information, Ministry of Health, Cambodia, Cambodia

Correspondence to Dr Peter Leslie Annear; pannear@unimelb.edu.au

\section{ABSTRACT}

Introduction Cambodia's health equity fund (HEF) is the country's most significant social security scheme, covering the poorest one-fifth of the national population. During the last two decades, the HEF system was scaled up from an initial two health districts to national coverage of public health facilities. This is the first national study to examine the impact of the HEF on the utilisation of public health facilities.

Methods We first investigated the level of national HEF population coverage and health service use made by HEF eligible members using an administrative HEF operational dataset. Second, through multilevel interrupted time series analysis of routine monthly utilisation statistics during 2006-2013, we evaluated the impact of the HEF on hospital and health centre utilisation.

Results The proportion of HEF beneficiaries using hospital services in a given year (4.6\%) appeared to exceed rates in the general population (3.3\%). The introduction of the HEF was associated with: a significant level change in the monthly number of consultations at HCs followed by a gradual slope increase in time trend and a significant level change in the monthly number of deliveries. Overall, this was equivalent to a $15.6 \%$ net increase in number of consultations and $5.3 \%$ in deliveries in the first year. At RHs: a significant level change in the number of RH inpatient cases, followed by a sustained slope increase; a significant slope increase in the number of outpatient consultations and in the overall number of newborn deliveries. Overall, this was equivalent to a $47.9 \%$ net increase in inpatient cases, $24.1 \%$ in outpatient cases and $31.4 \%$ in deliveries in the first year.

Conclusion The implementation of the HEF scheme was associated with increased utilisation of primary and secondary care services by the poor.

\section{INTRODUCTION}

Cambodia's national health equity fund (HEF) is the country's largest social health protection scheme, covering (at the time of our study) the poorest one-fifth of the national population (approximately 3 million
Summary box

What is already known?

- The health equity fund (HEF) often provides improved access to health services for the poor at district level.

- Health centres services accrue more than proportionally to the poor population.

- HEF reduces household debt for healthcare.

What are the new findings?

- The HEF met its original aim of providing improved access to government health facilities for poor people.

- The HEF successfully extends social health protection to the poor.

What do the new findings imply?

- The poor can be covered successfully in advance of the formal employment sector and the informal sector.

- The HEF provides the foundation for further development of social health protection in a low-middleincome country.

out of 15 million), and is the foundation for the emerging national social protection system. ${ }^{1}$ Initiated at two health districts in 2000, the HEF was designed to remove financial barriers and provide increased access to government health facilities for the poor (both those who did not previously seek care and those who used potentially more expensive and less effective private and non-medical services) (And, therefore, to reduce debt for health care, sale of household assets and catastrophic expenditures that derive from the use of private health services.). It was introduced initially at referral hospitals (RHs) and after 2008 widely also at health centres (HCs). By 2015, the HEF was scaled up to national coverage of all public health facilities. ${ }^{2}$ 
A 2010, comprehensive review of all then published and grey literature concluded that there was sufficient evidence to suggest that the HEF within the health districts included in these studies helped to raise utilisation levels at government facilities, to provide a significant source of additional revenue for public health facilities and to reduce (but not eliminate) debt for healthcare. ${ }^{3}$ Subsequent evidence, using national data from consecutive Cambodia Socio-Economic Surveys, suggested that the HEF had reduced the amount (but not the incidence) of out-of-pocket expenditure on healthcare by $35 \%$ on average (with a larger effect for poorer households) and reduced the amount of household debt for healthcare by $25 \%$ on average. ${ }^{4}$

An earlier analysis of Demographic and Health Survey 2000-2010 data showed impressive improvements in coverage of reproductive and maternal health services, with significant reductions in the gap between rich and poor. ${ }^{5}$ An analysis of routine Ministry of Health (MOH) data between 2014 and 2017 revealed that utilisation of maternal and child health services by HEF-supported patients had risen significantly both at HCs and at RHs. ${ }^{6}$ A broad ranging political analysis of the health sector and HEFs concluded that the HEF had expanded access for the poor and provided incentives for health facility staff but had not been able to address more deep-seated health system challenges related to adequate service delivery. ${ }^{7}$ A 2018, national cross-sectional survey concluded that about $32 \%$ of HC benefits went to the poorest $20 \%$ of the population and the benefit of RH inpatient services were substantially pro-poor. ${ }^{8}$

However, no previous study has investigated, on a national scale, the achievement of the HEF in meeting its original aim of providing increased access to government health facilities for the poor. This study evaluates the impact of the HEF on healthcare utilisation of public health facilities (as a proxy for access to care) using official national routine data. Specifically, we focus on the period 2006-2013, the most active period of HEF expansion.

High levels of out-of-pocket spending on healthcare in Cambodia-averaging more than $60 \%$ of total health expenditure over an extended period of time-have been associated with high levels of debt for healthcare and an often insurmountable barrier to access for the poor; of total out-of-pocket spending in 2012, $77 \%$ was in the private sector, where the poor are under-represented in access to care. ${ }^{9}$ Government health facilities have had the right to charge nominal, regulated user fees since 1996 (according to a schedule prescribed by the $\mathrm{MOH}){ }^{10-12}$ While the fees are low and provide less than a tenth of national government health expenditures, they have been an important operating revenue at facility level.

Although fee exemptions for the poor were mandated with the introduction of user fees in 1996, they were rarely offered by facilities due to the loss of income entailed. The HEF was designed specifically to protect facility revenues through funded exemptions for the poor. Additionally, because those eligible for HEF benefits live predominantly at subsistence level (below the poverty line measured as sufficient resources to provide only food and housing), the cash costs of food and transport to facilities have prevented access to care, a barrier lowered by the HEF, which provides cash transport and food subsidies. ${ }^{13}$

Internationally, user fees at government facilities have been a barrier to access in almost all low-income countries; their careful removal has been accompanied in most cases by increased facility utilisation. ${ }^{14-16}$ The HEF example demonstrates that funded fee exemptions are potentially as effective as the removal of user fees and work to protect supplementary facility revenues (as documented in the wider published literature on user fees) ${ }^{17}$

A 2009 WHO report described the HEFs as a major national achievement that had provided international evidence for designing health safety nets. ${ }^{18}$ HEFs became an integral part of the National Poverty Reduction Strategy 2003-2005 $5^{19}$ and the Health Strategic Plan 2003-2007.20 21 The MOH developed its first Strategic Framework for Equity Funds in 2003. ${ }^{1822}$ In 2005, the MOH adopted the National Equity Fund Implementation and Monitoring Framework. ${ }^{23} 24$ In 2006, the Ministry of Planning refined, streamlined and institutionalised the nationwide system for preidentification of the poor (known locally as IDPoor). In 2009, the $\mathrm{MOH}$ published the Implementation of Health Equity Funds Guideline ${ }^{25}$ and in 2016 the Health Equity Fund Operation Manual. ${ }^{26}$

The HEF system is cofunded by government taxation revenues and overseas development assistance, pooled nationally. The structure and financing of the HEF have changed over time. Originally, district-based HEFs were established and implemented by non-government organisations (NGOs). Later, a more unified national structure was developed and operated jointly by donor partners and NGOs under the stewardship of the MOH.

The HEF system covers services only at public health facilities. From the original two health districts in 2000, HEF schemes were implemented in 24 out of 76 health districts by 2006 (Annear, personal report available from pannear@unimelb.edu.au) and national coverage was achieved in, then, all 94 health districts by $2015 .^{26} 27$ During the period of this study, the HEF was managed at national level for the $\mathrm{MOH}$ by an international NGO designated as the 'HEF Implementer'. Within each health district, administration of the HEF was delegated to a subcontracted 'HEF Operator', a role carried out by different local NGOs. From 2017, these functions at both national and district levels were taken entirely into the $\mathrm{MOH}$ through an autonomous office funded jointly by the government and donors.

HEF beneficiaries are preidentified through the national IDPoor household survey. The IDPoor survey applies (by law) to all social sectors and is carried out nationally by the Ministry of Planning (with the support of the German government) in every district on a rolling 3 year basis; validation by the German government, the 
World Bank and others has found this poverty identification process to be more accurate than similar examples in other countries, though not completely free from inevitable identification errors. ${ }^{628}$ IDPoor offers a website database allowing users to register and access constantly up-to-date data (http://www.idpoor.gov.kh). Poor families not included in the survey are eligible for postidentification conducted at health facilities. The targeting process (which originally occurred at district level) was shown to result in the increased utilisation of public health services. ${ }^{49}$

The $\mathrm{MOH}$ issued a standard HEF benefit package and provider-payment policy in 2012, updated multiple times with the most recent version being released in 2018, that includes the full range of services defined in the Clinical Practice Guidelines for RH and HC services (excluding chemotherapy and radiation treatment, cosmetic surgery and non-medical treatments) and reimburses facilities for consultation fees, investigation costs, medicines and supplies that occur in addition to government budget allocations ${ }^{30}$ In addition, HEF beneficiaries receive transportation costs for attending hospital care or newborn delivery services at HCs; daily food allowances for caretakers of patients admitted to hospitals; and a funeral benefit in case of death while receiving treatment at a hospital.

\section{METHODS}

Our analyses consist of two interrelated components. First, we investigated the level of national HEF population coverage and health service admissions by HEF members, using the HEF beneficiary dataset. Second, we assessed the impact of HEF on the utilisation of RH and $\mathrm{HC}$ services in all RH and HC facilities nationally, using data from the MOH's Health Management Information System (HMIS).

The member-based HEF Operational Database was developed in stages by the HEF Implementer and the $\mathrm{MOH}$ as an administrative tool to track HEF beneficiaries for the purpose of making payments and auditing facilities. We merged beneficiary files to make a complete dataset that included 2.6 million admissions between January 2004 and June 2013. HEF population coverage was calculated using the HEF Implementer record of enrolled households. We analysed descriptive information for HEF member admissions at RHs and HCs for type of facility visit (inpatient, outpatient, health clinic), and benefit paid (user fee, transport, food), including age-based data suggesting use of services by women and children.

Retrospective HMIS health facility data were fully available electronically for all RHs and HCs nationally from 2006. The computerised, online system included monthly data for all RHs and HCs. For the purpose of the study, we collected utilisation data for each month during the period January 2006 to December 2013, a total of 96 data points. Earlier utilisation data were not available in electronic format. The HMIS has been assessed as a reliable data source. ${ }^{31}$

The total number of RHs and HCs nationally expanded over time and HEF schemes were introduced into districtbased facilities at different points in time. Every RH and HC for which HMIS data were available were included in the analysis. This included 62 of a total 79 RHs operating nationally in 2013, comprising the two HEF participating RHs in Phnom Penh with the rest in rural locations and towns. (Additional $15 \mathrm{MOH}$-designated National Hospitals and disease-control centres located in Phnom Penh were not included as all but one were outside the HEF.) All 1081 HCs in operation in 2013 were included in the study, of which 19 were located in Phnom Penh.

Our study examined five key outcomes that measured levels of utilisation at public health facilities. For RHs: (1) number of admissions to the inpatient department (IPD); (2) number of visits to the outpatient department (OPD); (3) number of newborn deliveries. For HCs: (4) number of consultations; (5) number of newborn deliveries. For all five variables, the data were based on a count of cases per facility aggregated by month over the full 96 data points.

There were, however, significant periods of missing monthly data from some facility records, and some new facilities had not collected data. A count of the months of missing data as a proportion of all months across 96 data points and all RHs and HCs revealed gaps of 23.9\%, 22.3\%, and $59.5 \%$ for $\mathrm{RH}$ outpatient, inpatient and newborn delivery outcomes, respectively; at HCs, the proportion was $11.1 \%$ for both consultations and newborn deliveries. Despite the high proportion of missing data for RH newborn deliveries, we maintained this measure in the study both because we feel it is important to report the outcomes of this first-ever study using national HMIS administrative data (of which, the level of missing data is one) and because we aimed to capture potential patient cross-over in facility use for newborn deliveries between RHs and HCs as a part of our analysis.

During this period, the district-based HEF had been implemented alongside other schemes. We controlled for all such schemes with significant effect, as follows:

- A government scheme that reimbursed user fee exemptions in selected non-HEF health facilities, known as Subo and introduced in $2006 .{ }^{32}$

- The contracting of government service delivery, initially to NGO facility managers (external contracting, 1997-2009) and later between different levels within the $\mathrm{MOH}$ (internal contracting, from 2009). ${ }^{33} 34$

- A government-funded midwife incentive that paid US $\$ 10-15$ per live delivery at RHs and HCs, implemented nationally during 2006-2007.

- Vouchers provided by NGOs to pregnant women to access free maternal services at RHs and HCs from 2007 in four health districts, and in 23 by 2013.

- A Global Alliance for Vaccine Initiatives (GAVI)funded performance-based incentive designed to 
Table 1 Number and public health facilities and health equity fund (HEF) coverage, 2006-2013

\begin{tabular}{lrrrrrrrr}
\hline Facility & $\mathbf{2 0 0 6}$ & $\mathbf{2 0 0 7}$ & $\mathbf{2 0 0 8}$ & $\mathbf{2 0 0 9}$ & $\mathbf{2 0 1 0}$ & $\mathbf{2 0 1 1}$ & $\mathbf{2 0 1 2}$ & $\mathbf{2 0 1 3}$ \\
\hline Health operational districts & 77 & 77 & 77 & 77 & 77 & 77 & 79 & 81 \\
\hline Total referral hospitals & 79 & 79 & 79 & 80 & 81 & 82 & 83 & 86 \\
Referral hospitals with HEF & 25 & 27 & 42 & 42 & 43 & 43 & 45 & 45 \\
Total health centres (functioning) & 956 & 959 & 960 & 962 & 970 & 995 & 1019 & 1081 \\
Health centres with HEF & 16 & 17 & 81 & 168 & 246 & 277 & 301 & 476 \\
\hline
\end{tabular}

Source: Annual Health Financing Report 2015, Ministry of Health.

improve immunisation, antenatal care and integrated management of childhood illness in selected health districts.

We used an interrupted time series (ITS) study design to evaluate the impact of HEF on trends in utilisation at health facilities. This ITS model estimates both the level change in the variable (at the point the HEF was introduced at a facility) and slope change in time trend after HEF implementation. The regression model includes a dummy variable for the period before implementation (coded as 0 ) and after implementation (coded as 1). The model also includes a continuous variable equal to the number of months since the HEF took effect for each healthcare facility. Our analyses are adjusted to capture any secular time trend during the study period, including population growth over the study period, seasonal effect (dummy variable for each month) and the five concurrent policies mentioned above.

To take account of the multilevel nature of the datahealthcare facilities being observed many times in the panel, and health facility nested at the district-a mixed-effect multilevel model was fitted. The ITS multilevel model specification is: $y_{i j t}=B_{0}+B_{1}$ time $e_{i j t}+B_{2}$ policy $y_{i j t}$ $+B_{3}$ years_after_policy $y_{i j t}+B_{4} X_{i j t}+v_{i}+{ }_{u j}+e_{i j t}$ where: $v_{i}, \mathrm{u}_{\mathrm{j}}$, are random intercepts for district level and facility level and are assumed to be independently distributed from the residual error $e_{i j t} ; B_{1}$ estimates the average change in the outcome measures that occur each month during the study period; $B_{2}$ estimates the level change in outcome measures after HEF was introduced; $B_{3}$ estimates the average change in outcome measures in the period following introduction of the HEF; $B_{4}$ is the vector of estimates corresponding to the vector of covariates that are used to control for other confounding variables including monthly dummy variables and concurrent policies.

We calculated the means of outcomes before and after the point of intervention for both RHs and HCs. We compared the changes in outcomes between two groups using t-tests. We used the bootstrap method with 2000 replications to estimate the SE of parameter estimates. We conducted sensitivity analyses to compare $\mathrm{RH}$ results including all RHs with results excluding three large urban hospitals in Phnom Penh, Battambang and Banteay Meanchey that had implemented HEF early (during or before 2006) and had very high volumes of utilisation. Statistical analyses were undertaken using STATA V.15.

\section{RESULTS \\ HEF beneficiary analysis}

During the period May 2014-April 2015, a total of 3 229044 individuals were identified nationally (across all 94 health districts) through the IDPoor survey and postidentified at facilities and comprised the national cohort eligible to receive $\mathrm{HEF}$ benefits. According to our estimates, the proportion of all HEF beneficiaries using public RH services in this period was $4.6 \%$ (based on data from the HEF membership database) compared with $3.3 \%$ of the national population using public RH services generally (based on data from the Cambodia Socio-Economic Survey 2014). The number of health districts expanded nationally over time, in line with population growth (table 1). HEF coverage of RHs nationally increased from one-third to more than one-half of all RHs during 2006-2013 while HC coverage increased from less than $2 \%$ to almost half of all HCs-which led to a steep rise in total facility visits by HEF beneficiaries during 2006-2013 (figure 1).

On average, HEF patients travelled less than $10 \mathrm{~km}$ to a health facility: the proportion of patients living within $1 \mathrm{~km}$ of a facility was $38 \%$, within $5 \mathrm{~km} 75 \%$ and within $10 \mathrm{~km} 98 \%$. Patients travelled $20.7 \mathrm{~km}$ on average for hospital inpatient services and $23.3 \mathrm{~km}$ for outpatient services. The most common distance travelled was 1.6 $\mathrm{km}$ to a HC, $4.0 \mathrm{~km}$ for outpatient care at a hospital and $11.7 \mathrm{~km}$ for an inpatient visit. On average, HEF patients visiting health facilities were 27 years old, with outpatient users slightly older (32) and HC users slightly younger

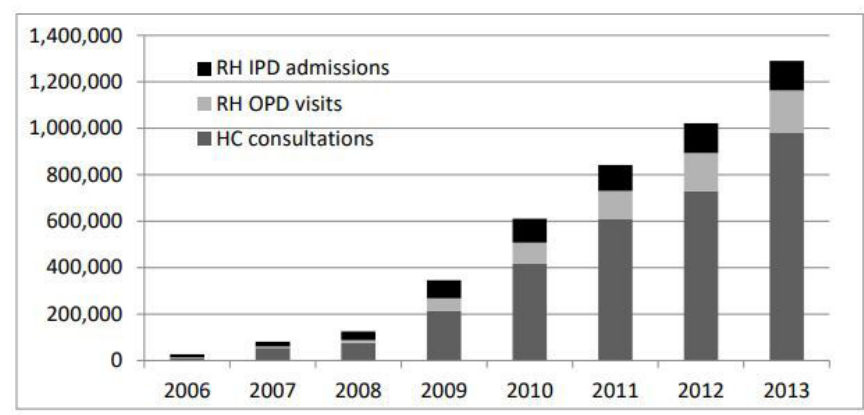

Figure 1 Total health equity fund member visits by facility type and year, 2006-2013. HC, health centre; IPD, inpatient department; OPD, outpatient department; $\mathrm{RH}$, referral hospital. 


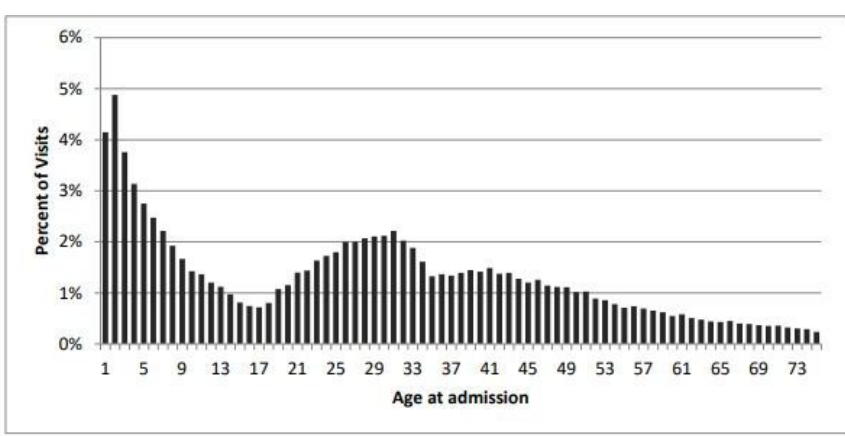

Figure 2 Distribution of health equity fund patients by age at admission, 2000-2012.

(25) (figure 2). A fifth of all facility visits were for infants and children, suggesting that HCs were an important site for maternal and child healthcare.

Of the total number of facility visits during 2006-2013, $63 \%$ occurred at HCs and the remainder were evenly split between hospital IPD and OPD departments. For inpatient admissions, the average length of stay was 6.6 days, compared with a national average of 4.9 days for hospitals outside of Phnom Penh, suggesting that HEF benefits may encourage a longer stay in hospital. It appears that $12 \%$ of inpatient visits and $20 \%$ of outpatient visits at hospital level were for newborn deliveries. Almost $10 \%$ of $\mathrm{HC}$ visits were for antenatal care or reproductive health.

\section{Utilisation of health facilities}

The results of the regression analysis of health facility utilisation are listed in table 2. We deal first with $\mathrm{HC}$ results and then with RHs.

\section{Health centres}

Of the $1081 \mathrm{HCs}, 476$ (44\%) had commenced an HEF at some point during 2006-2013. The mean monthly number of new-case consultations per $\mathrm{HC}$ was 588.9 in the period prior to HEF, and this increased to 701.4 in the period after the HEF was implemented $(\mathrm{p}<0.001)$ at facilities. The mean monthly number of newborn deliveries per $\mathrm{HC}$ was 9.4 in the period prior to HEF and 14.6 in period after the HEF was implemented $(\mathrm{p}<0.001)$.

Results from our multilevel regression model suggest that the introduction of HEF was associated with a statistically significant level change in the monthly number of new-case consultations ( $\mathrm{b}=88.3 ; 95 \%$ CI 82.0 to 94.6 ; $\mathrm{p}<0.001$ ); (Where: $\mathrm{b}$ is the average increase of the level of monthly number of new cases; 95\% CI denotes $95 \%$ confidence that the true results lie within the range 82.094.6 new case consultations per month; $\mathrm{p}<0.001$ denotes confidence at less than 1 in 1000 chance of being wrong.) this was followed by a relatively small but sustained gradual slope increase in time trend ( $b=3.7 ; 95 \%$ CI 1.4 to 5.9; $\mathrm{p}<0.001$ ) (Where $\mathrm{b}$ is the average increase in the slope of time trend in monthly number of new cases.). These results show an equivalent average increase of $15.6 \%$ (That is, an average increase in level (88.3) plus slope (3.7) of new-case consultations per month (total 92.0) following HEF introduction above the previous monthly average of 588.9 new-case consultations per month prior to HEF implementation.) in the monthly number of HC new-case consultations in the first year following HEF introduction, after adjusting for the underlying time trend (with a continued slope increase in following years). For the monthly number of newborn deliveries, the introduction of HEF was associated with a significant level change ( $b=0.5 ; 95 \%$ CI 0.4 to $0.7 ; p<0.001)$, but there was no statistically significant slope change in time trend. These results show an equivalent average increase of $5.3 \%$ in the monthly number of HC newborn deliveries in the first year following HEF introduction (with a continued slope increase in following years).

\section{Referral hospitals}

Of the 62 RHs in our study, $46(74.2 \%)$ had commenced HEF at various times during 2006-2013. The mean monthly number of outpatient consultation per hospital was 245.2 prior to HEF; this rose to 1049.7 in the period following introduction of HEF at each facility $(p<0.001)$. The mean monthly number of inpatient cases per hospital in the period prior to the HEF implementation was 141.7; this increased to 447.8 in the period with HEF $(p<0.001)$. The mean monthly number of hospital newborn deliveries per hospital was 48.0 in period without HEF, and this number increased to 73.8 in period with HEF $(\mathrm{p}<0.001)$. Three large urban hospitals in Phnom Penh, Battambang and Banteay Meanchey had implemented HEF early (during or before 2006) and had very high volume of utilisation; sensitivity analysis showed that this did not significantly affect the overall trend.

Results from our multilevel regression model suggest that the introduction of HEF was associated with a statistically significant slope increase in time trend in the number of outpatient consultations ( $b=59.2 ; 95 \%$ CI 43.8 to 74.6 ; $\mathrm{p}<0.001$ ), but there was no statistically significant level change. These results show an equivalent average increase of $24.1 \%$ in the monthly number of RH outpatient consultations in the first year following HEF introduction (with a continued slope increase in following years).

For the monthly number of inpatient cases, the introduction of HEF was associated with a statistically significant level change ( $b=38.6 ; 95 \%$ CI 25.9 to 51.2; $p<0.001$ ); this was followed by a large, gradual, sustained slope increase in time trend ( $\mathrm{b}=29.4 ; 95 \%$ CI 26.6 to 32.3; $\mathrm{p}<0.001)$. These results show an equivalent average increase of $47.9 \%$ in the monthly number of RH inpatient consultations in the first year following HEF introduction (with a continued slope increase in following years).

The introduction of HEF was associated with a significant slope increase in time trend in the overall number of newborn deliveries $(b=15.1 ; 95 \%$ CI 4.8 to 25.6 ; $p<0.05)$, but there was no statistically significant level change. These results show an equivalent average increase of $31.4 \%$ in the monthly number of $\mathrm{RH}$ outpatient consultations 


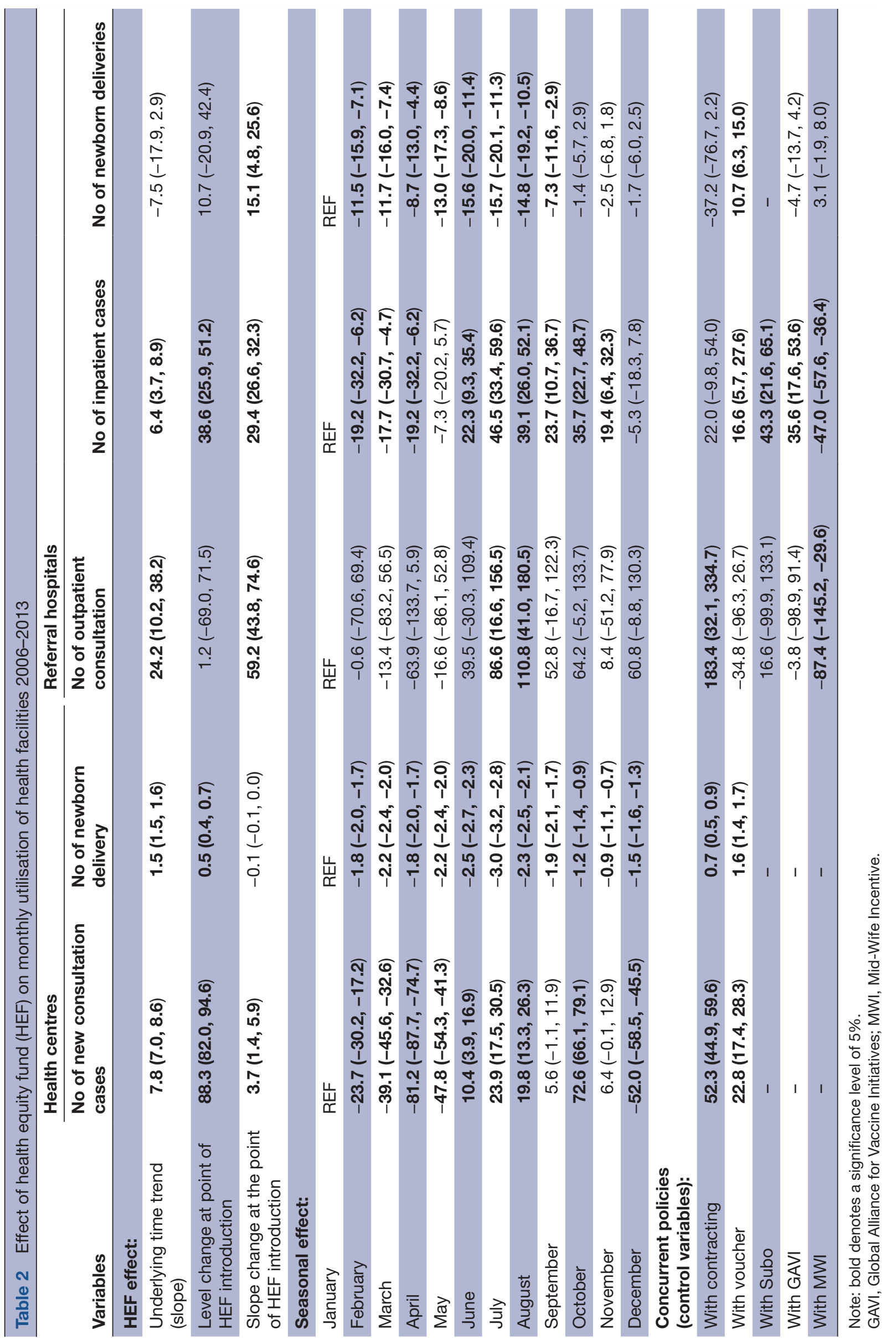


in the first year following HEF (with a continued slope increase in following years).

Results from sensitivity analyses, excluding data from three major hospitals that had very high levels of utilisation, were largely comparable to those including all RHs (as demonstrated in online Appendix Table 1). The introduction of HEF was associated with a statistically significant slope increase in number of outpatient consultations ( $\mathrm{b}=40.1 ; 95 \%$ CI 27.8 to 52.4$)$, but there was no statistically significant level change. The introduction of HEF was associated with a statistically significant level change in the number of inpatient cases ( $b=41.9 ; 95 \%$ CI 30.8 to 53.2); this was followed by a large sustained gradual slope increase time trend in number of cases ( $b=27.8 ; 95 \%$ CI 25.3 to 30.3). The introduction of HEF was associated with a significant slope increase in time trend in the overall number of newborn deliveries ( $b=10.8 ; 95 \%$ CI 4.1 to 17.5 ), but there was no statistically significant level change.

\section{Control variables}

Our results show a positive impact of most control variables on increased utilisation in the first year following introduction (table 2):

- The largest effect overall was of contracting on RH OPD consultations, though with wide variation $(\mathrm{b}=183.4 ; 95 \%$ CI 32.1 to 334.7 ; $\mathrm{p}<0.001)$; the HEF in contrast raised the trend but not the level of OPD consultations.

- Contracting had no significant effect on IPD admissions or RH newborn deliveries.

- The presence of contracting and voucher schemes was associated with an increased number of HC new cases, though at a lower level than the HEF.

- The monthly number of IPD cases was increased by vouchers, Subo (which paralleled the HEF) and GAVI, though the most consistent impact on level and trend appears to come from the HEF.

- The largest impact on newborn deliveries at HCs and RHs was the maternal voucher scheme: HCs (no available data); RHs ( $b=10.7$; $95 \%$ CI 6.3 to $15.0 ; \mathrm{p}<0.001)$; the impact of the HEF on RH newborn deliveries was in the same magnitude but was not statistically significant.

- Interestingly, the mid-wife incentive reduced OPD consultations and IPD cases, perhaps by helping to avoid complications.

\section{DISCUSSION}

Our study analysed monthly health facility utilisation data for the most active period of HEF scaling up, which allowed for a comparison of facilities with and without the HEF across the period. Our results show that the HEF was associated with rising utilisation levels at government HCs and RHs. The study confirms that HEF members as identified by the national IDPoor survey made use of $\mathrm{HC}$ and $\mathrm{RH}$ services in greater proportion than among the general population (where use of private facilities is much greater).

At the same time, across the national population less than one-in-four $(23.5 \%)$ ill or injured persons sought care first at a public facility ( $64 \%$ at a private practitioner and $13 \%$ using self-care, traditional healers or other facilities). ${ }^{35}$ Therefore, while the HEF provided improved access to government services for the poor, caution is needed in interpreting the results of this study in relation to meeting household needs for care and avoiding unaffordable costs.

Our findings show that the HEF was associated with a significant increase in hospital care $(47.9 \%$ in the number of inpatient cases, $24.1 \%$ increase in outpatient cases and $31.4 \%$ in hospital deliveries in the first year after HEF), and in HC care $(15.6 \%$ in number of consultations, $5.3 \%$ in HC deliveries in the first year after HEF).

All age groups among the poor benefited from the introduction of HEF, but utilisation was the highest in the 1-9 years and $20-35$ years age groups. This is likely to reflect a felt need for reproductive, maternal and child health in a country that was emerging from an earlier period of high fertility, high maternal mortality and high infant mortality into a more sustainable era of adequate healthcare. The growing number and distribution of RHs and HCs during the study period help to reduce the geographic barrier to access to services for the entire population, though the poor still faced the financial barrier. This financial barrier was reduced at those HCs-located most commonly within $1.6 \mathrm{~km}$ of home-where HEF was provided, with a consequent rise in utilisation. Similar increases in utilisation by the poor were not evident at HCs without HEF (or a similar scheme such as vouchers). Today, all HCs are covered by HEF and the parallel schemes (like vouchers) have been rolled into the HEF.

Divergence in the results between hospitals and HCs raises a number of questions for further qualitative research. Because the HEF was introduced at HCs chronologically later than at RHs, it is likely that utilisation gains at RHs predate those at HCs; with elimination of the financial barrier at HCs, poor patients may have moved their attendance from the RH for similar services offered at the HC: for example, the significant level increase for HC consultations while RH OPD showed only a trend increase after HEF. It appears also that access to newborn delivery services may have shifted from the RH to the closer HC or that mothers felt the HEF provided access to nearby facility services they had not previously used (for perhaps cultural reasons like proximity of family).

The threefold increase in RH inpatient utilisation is notable: it was, though, not possible to determine the cause. Three contextual factors should perhaps be kept in mind: (1) that the HEF removed the significant financial barrier at RHs (where user fees and under the table charges discouraged access by the poor); (2) there had been a significant unmet need for hospital care among the poor prior to HEF; (3) the expansion of the hospital 
infrastructure over time provided a capacity and level of service that had not previously existed, though financial barriers remained for the poor prior to the HEF. Consequently, the increased level of utilisation is likely to have taken up existing but unused capacity at the hospital level. Additionally, by reimbursing fee exemptions, the HEF provided increased revenue and a financial incentive to hospitals to increase service provision without sacrificing the existing quality of care.

There are important caveats to our statistical analysis. First, the ITS model provides only a limited causal interpretation of the results. Second, the HEF was implemented in Cambodia in the context of ongoing change: population growth, urbanisation, economy growth, falling poverty rates, expansion of the government health system (along with the growth of a varied private sector) and introduction of a number of innovative health financing initiatives in many health districts. Third, the high proportion of missing data for RH newborn deliveries means that this measure must be treated with particular caution; we have, however, maintained this measure due to its importance in the overall analysis.

While our model adjusted for the underlying time trend and concurrent financing policies, the prevailing circumstances make it difficult to evaluate precisely the impact of any one intervention on the level of health facility utilisation. Among the limitations of this study, the most significant is the missing monthly data in $\mathrm{HC}$ and RH records entered into the HMIS. In general, the $\mathrm{RH}$ data quality was less robust than for HCs, due to greater inconsistency in reporting. There was no statistically reliable way to impute the missing data. Even so, we believe the trend over 96 months of data and across all health facilities (where data were missing at different time periods in each facility) was sufficient to say that our results remain valid.

\section{CONCLUSION}

The findings indicate that the implementation of the HEF scheme was associated with increased utilisation of government primary and secondary care services by the poor. Taken together, our results confirm the body of partial evidence that suggests that the HEF has been effective in meeting its stated goals. This increased utilisation of government services may have come both from those who previously had not routinely accessed healthcare and by attracting patients away from potentially more costly and less-effective private (often non-medical) services. Both were the original intent of the HEF. The HEF has been at the centre of the long-term process of national health reform and is now officially the foundation for the expansion of social health protection (and social protection in general) across Cambodia. ${ }^{36}$ Other significant demand-side schemes (vouchers, GAVI) have been subsumed within the national HEF; supplyside interventions (contracting and performance-based incentives) have been packaged with the HEF as a uniform approach.

In moving towards universal health coverage, WHO has recommended an approach that first provides highpriority health services to everyone while ensuring that the poor and disadvantaged groups are not left behind. ${ }^{37}$ As part of an overall strategy, countries have been advised to make careful choices within as well as across health service dimensions while avoiding unacceptable tradeoffs that disadvantage the poor. This notion of progressive universalism has been the basis of health systems development, for example, in Thailand. ${ }^{38}{ }^{39}$ In Cambodia, the growth and development of the HEF provide another example of extending social health protection to the poor in advance of covering the formal employment sector and the informal sector. Our study is a contribution to the evidence base for the further development of social health protection in the setting of a low-middleincome country.

Acknowledgements The authors thank the Ministry of Health for its cooperation and support. The National Institute of Public Health, Cambodia, and the University Research Co. LLC Phnom Penh office were partners in the grant together with colleagues from the Harvard TH Chan School of Public Health.

Contributors All authors provided time and information for the preparation, writing and review of this article. The principal author is PLA. JL and EM carried out the main quantitative analysis. PI and KK obtained the dataset from the HMIS cleaned and managed the data, and carried out the initial quantitative analysis. VL gave access to the data, advised the research team and provided technical support to the research. TB reviewed and corrected the draft article and supervised the participation of Harvard University in the project. TJ provided, cleaned and managed raw data from the HEF membership database and provided detailed information for the manuscript. MN supervised data collection and analysis and provided an original draft of results.

Funding This research project was carried out with funding from the Australian Government through AusAID and the Department of Foreign Affairs and Trade under an Australian Development Research Award to the Nossal Institute for Global Health, the School of Population and Global Health, The University of Melbourne.

Competing interests None declared.

Patient consent for publication This study analysed anonymous, routine health facility data. No patients were involved in any way in this study. There was no public involvement.

Provenance and peer review Not commissioned; externally peer reviewed.

Data availability statement Data used in this study were downloaded - with the permission and the approval of the Ministry of Health-from the Cambodia Health Management Information System. The intellectual property of the HMIS remains with the Cambodia Ministry of Health. The raw data are available on request from the Ministry of Health.

Open access This is an open access article distributed in accordance with the Creative Commons Attribution Non Commercial (CC BY-NC 4.0) license, which permits others to distribute, remix, adapt, build upon this work non-commercially, and license their derivative works on different terms, provided the original work is properly cited, appropriate credit is given, any changes made indicated, and the use is non-commercial. See: http://creativecommons.org/licenses/by-nc/4.0/.

ORCID iD

Keovathanak Khim http://orcid.org/0000-0002-8604-0323

\section{REFERENCES}

1 Royal Government of Cambodia. National social protection policy framework 2016-2025.Approved by the Council of ministers on 24 March 2017, 2017. Available: http://inndec.com/library/docs/SPPF\% 20English\%20-\%20Final\%20Ver.pdf 
2 Annear PL, Khim K, Ir P, et al. National coverage and health service utilization by Health Equity Fund members, 2004-2015. ADRA Research Report, The University of Melbourne, 2016. Available: http://mspgh.unimelb.edu.au/_data/assets/pdf_file/0006/2074965/ Annear-ADRA-Research-Report.pdf [Accessed 20 Mar 2019].

3 Annear PL. A comprehensive review of the literature on health equity funds in Cambodia 2001-2010 and annotated bibliography. health policy and health finance knowledge hub working paper No.9 2010. Nossal Institute for Global Health, The University of Melbourne, 2010.

4 Flores G, Ir P, Men CR, et al. Financial protection of patients through compensation of providers: the impact of health equity funds in Cambodia. J Health Econ 2013;32:1180-93.

5 Dingle A, Powell-Jackson T, Goodman C. A decade of improvements in equity of access to reproductive and maternal health services in Cambodia, 2000-2010. Int J Equity Health 2013;12:51.

6 Kaba MW, Baesel K, Poch B, et al. IDPoor: a poverty identification programme that enables collaboration across sectors for maternal and child health in Cambodia. BMJ 2018;363.

7 Kelsall T, Heng S. Inclusive healthcare and the political settlement in Cambodia. New Political Economy 2016;21:238-55.

8 Asante AD, Ir P, Jacobs B, et al. Who benefits from healthcare spending in Cambodia? Evidence for a universal health coverage policy. Health Policy Plan 2019;34:i4-13.

9 Annear PL, ed. The Kingdom of Cambodia health system review. health systems in transition, 2015 5:2. Asia Pacific Observatory on health systems and policies and the world Health organization, 2019. http://www.searo.who.int/entity/asia_pacific_observatory/ publications/APO Cambodia/en

10 Bigdeli M, Ir P. A role for user charges? Thoughts from health financing reforms in Cambodia. World Health Report 2010, Background Paper No. 42 2010. Geneva: World Health Organization, 2010.

11 Annear PL, Bigdeli M, Ros CE, et al. Providing access to health services for the poor: Health equity in Cambodia. Studies in HSO\&P. Antwerp: Institute for Tropical Medicine, 2008: 23. 189-225.

12 Wilkinson D, Holloway J, Fallavier P. The impact of user fees on access, equity and health provider practices in Cambodia. Phnom Penh, Ministry of Health/World health organization health sector reform phase III project 2001.

13 Annear PL, Khim K, Ir P, et al. National coverage and health service utilization by health equity fund members, 2004-2015. ADRA research report, the University of Melbourne 2016. Available: http://mspgh.unimelb.edu.au/_data/assets/pdf_file/0006/ 2074965/Annear-ADRA-Research-Report.pdf [Accessed 20 Mar 2019].

14 McPake B, Brikci N, Cometto G, et al. Removing user fees: learning from international experience to support the process. Health Policy Plan 2011;26:ii104-17.

15 Lagarde M, Palmer N. The impact of user fees on access to health services in low- and middle-income countries. Cochrane Database Syst Rev 2011:CD009094.

16 Meessen B, Gilson L, Tibouti A. User fee removal in low-income countries: sharing knowledge to support managed implementation. Health Policy Plan 2011;26:ii1-4.

17 Meessen B, Van Damme W, Tashobya CK, et al. Poverty and user fees for public health care in low-income countries: lessons from Uganda and Cambodia. Lancet 2006;368:2253-7.

18 Antunes AF, Wanert S, Bigdeli M, et al. Summary report of the health financing system assessment in Cambodia. Phnom Penh: World Health Organization, 2009. https://www.who.int/health_financing/ documents/cov-oasis_e_09-cambodia/en/

19 Council for Social Development. Cambodia National Poverty Reduction Strategy 2003-2005. Royal Government of Cambodia, 2002. Available: https://www.imf.org/External/NP/prsp/2002/khm/ 01/122002.pdf [Accessed 20 Mar 2019].
20 Ministry of Health. Health strategic plan 2003-2007. Phnom Penh, 2002.

21 Örtendahl C, Donoghue M, Pearson M, et al. Health sector review (2003-2007) Cambodia. HLSP London 2007. Available: https:// camnut.weebly.com/uploads/2/0/3/8/20389289/2007healthsector review2003-2007.pdf [Accessed 29 Jun 2019].

22 Ministry of Health. Strategic Framework for Equity Funds. In: Phnom Penh. Phnom Penh, 2003.

23 Ministry of Health. National equity fund implementation and monitoring framework. Phnom Penh, 2005.

24 World Health Organization and Ministry of Health. Scaling up for better health in Cambodia: a country case study for the world Health organization in follow-up to the high-level forum on the health millennium development goals. WHO/HDS/2007, 2007. Available: https://www.who.int/healthsystems/strategy/scaling-up_better health_Cambodia.pdf [Accessed 29 Jun 2019].

25 Ministry of Health. Implementation of health equity funds guideline. Phnom Penh, 2009.

26 Ministry of Health. Health equity fund operation manual. Phnom Penh, 2016.

27 Ministry of Health. Health strategic plan 2016-2020. Phnom Penh, 2019. http://hismohcambodia.org/public/fileupload/carousel/HSP3-( 2016-2020).pdf

28 Federal Ministry of Economic Cooperation and Development (Germany). Leave no one behind: Insights from Cambodia's national poverty identification system. A publication of the German Health Practice Collection, 2019. https://health.bmz.de/ghpc/case-studies/ leave-no-one-behind/ID_POOR_Final_lowres.pdf

29 Jordanwood T, van Pelt M, Grundman C. Evaluation report: health equity funds implemented by URC and supported by USAID. University Research Company, 2009.

30 Ministry of Health. Guidelines for the benefit package and provider payment of the health equity fund for the poor. Phnom Penh, 2018.

31 Ministry of Health. HMIS Bulletin. In: Effective health information system management is a contributing factor in better decisions and quality health service provision. Phnom Penh, 2012.

32 Men CR, Ir P, Annear PL, et al. Evaluation of subsidy schemes under Prakas 809 to support the Ministry of health of Cambodia to achieve universal social health protection coverage: report, December 2011. Phnom Penh (available from the authors pannear@unimelb.edu.au: Belgian Technical Cooperation, 2011.

33 Khim K, Ir P, Annear PL. Factors driving changes in the design, implementation, and Scaling-Up of the contracting of health services in rural Cambodia, 1997-2015. Health Syst Reform 2017;3:105-16.

34 Vong S, Raven J, Newlands D. Internal contracting of health services in Cambodia: drivers for change and lessons learned after a decade of external contracting. BMC Health Serv Res 2018;18:375.

35 National Institute of Statistics. Cambodia socio-economic survey 2014. Phnom Penh: Ministry of Planning, 2014

36 Royal Government of Cambodia. National social protection policy framework 2016-2025. Approved by the Council of ministers on 24 March 2017. 24, 2017.

37 World Health Organization. Making fair choices on the path to universal health coverage: final report of the who consultative group on equity and universal health coverage. Geneva, 2014. http://apps. who.int/iris/bitstream/10665/112671/1/9789241507158 eng.pdf

38 Starr C. Health 2015: A conversation with Davidson Gwatkin on Progressive Universalism. Results for Development 2014-0225;12:26, 2015. Available: http://www.r4d.org/blog/2014-02-25/ health-2015-conversation-davidson-gwatkin-progressiveuniversalism [Accessed 20 Mar 2019].

39 Tangcharoensathien V, Prakongsai P, Limwattananon S. From targeting to universality: Lessons from the Health System in Thailand. In: Townsend P, ed. Building Decent societies: rethinking the role of social security in development. Houndmills, Basingstoke, Hampshire: Palgrave Macmillan, 2009: 310-22. 